\title{
Role of Imaging in Acute Ischemic Stroke
}

Andrew A. Pavlina, MD, Rupa Radhakrishnan, MD, Achala S. Vagal, MD, MS

\author{
Authors: \\ Andrew Pavlina, MD: Resident Physician, Department of Radiology, University of \\ Cincinnati Medical Center, Cincinnati, $\mathrm{OH}$. \\ Rupa Radhakrishnan, MD: Assistant Professor of Radiology, Department of Radiology \\ and Imaging Sciences, Indiana University School of Medicine, Indianapolis, IN. \\ Achala Vagal, MD, MS: Associate Professor of Radiology, University of Cincinnati \\ Medical Center, Cincinnati, $\mathrm{OH}$. \\ Corresponding Author Information:
}

Andrew Pavlina, MD: Department of Radiology, University of Cincinnati Medical Center, 234 Goodman Street, Cincinnati, Ohio, 45267. Email: pavlinaw@ucmail.uc.edu

All work was performed at the University of Cincinnati Medical Center.

This work was not supported by grant funding.

This is the author's manuscript of the article published in final edited form as:

Pavlina, A. A., Radhakrishnan, R., \& Vagal, A. S. (2018). Role of Imaging in Acute Ischemic Stroke. Seminars in Ultrasound, CT and MRI. https://doi.org/10.1053/j.sult.2018.01.002 


\begin{abstract}
:
Rapid multimodal imaging is essential in the workup and management of acute ischemic stroke. Early parenchymal findings on non-contrast CT or standard MRI are used to triage patients for intravenous thrombolysis and to provide insight on prognosis. In the wake of recent endovascular stroke trials, advanced techniques including perfusion imaging and noninvasive vascular imaging are becoming important tools to guide potential endovascular treatment or expand therapy windows. Advanced imaging is also important in pediatric ischemic stroke which requires a slightly different workflow and treatment approach. Here, we will discuss key imaging findings in acute ischemic stroke, as well as the present and future of neuroimaging in light of recent and ongoing clinical trials.
\end{abstract}




\section{Introduction:}

The critical component of acute ischemic stroke (AIS) management is early revascularization of at-risk but potentially salvageable brain tissue, which can be viable for a period of time due to collateral perfusion ${ }^{1}$. The role of imaging in acute ischemic stroke is therefore to identify affected brain parenchyma and to delineate any areas of potentially salvageable tissue with the goal of early intervention and reperfusion.

With the success of recent endovascular therapy trials, there has been a paradigm shift from use of Intravenous tissue-type plasminogen activator (IV-tPA) alone to the addition of early endovascular therapy in appropriately selected patients. Intravenous tPA alone is generally better for reperfusion of small distal vessel occlusions than large proximal occlusions ${ }^{2,3}$ Rapid multimodal imaging is therefore critically important to identify patients who may benefit most from endovascular therapy. The use of various rapid imaging techniques has been an integral component of recent major stroke trials and are detailed in this review. $4,5,6,7$ With the use of advanced CT imaging tools, the time taken from stroke onset to first reperfusion has not substantially increased in some trials. ${ }^{8}$ However, there are a few additional recent trials which have used MRI and perfusion imaging to identify patients eligible for endovascular therapy or thrombectomy up to 6 to 24 hours after stroke symptom onset. ${ }^{9,10}$ Another important area of research is the use of MRI to identify eligible candidates for thrombolysis when symptom onset is unknown. ${ }^{11}$

Here, we discuss the parenchymal imaging findings of AIS with a focus on multimodal CT and MRI including angiographic and perfusion imaging. We will also describe how 
multimodal imaging can be incorporated into the existing stroke imaging workflow and briefly discuss imaging in pediatric ischemic stroke.

\section{CT Parenchymal Findings:}

Non-contrast enhanced CT (NCCT) remains a first-line imaging technique in the evaluation of suspected acute ischemic stroke. It is used to rapidly assess for any mimics of acute stroke and to identify evidence of an intracerebral hemorrhage which would contraindicate intravenous tissue plasminogen activator (IV tPA) therapy. ${ }^{12,13}$

Parenchymal findings of AIS can be detected very early with NCCT, with abnormalities found in up to $75 \%$ of patients with MCA stroke within 3 hours. ${ }^{14}$ When AIS occurs there is an increase in intracellular water, or cytotoxic edema, in the affected parenchyma.

This manifests on NCCT as decreased attenuation of tissue, loss of gray-white matter differentiation, and focal swelling which can lead to effacement of the sulci or mass effect (Fig. 1A, 1B). In the setting of MCA territory infarct, the loss of tissue attenuation can be detected early in the basal ganglia, particularly in the lentiform nucleus. Another early sign of MCA territory infarct is loss of gray-white differentiation at the insular cortex which is known as the "insular ribbon sign." These findings can be subtle in the early time windows and it is important to use narrow window settings to detect them. ${ }^{13}$ NCCT can also allow direct visualization of a hyperdense thrombus in an occluded artery (Fig. 1C), known as the "dense vessel sign." In the setting of low hematocrit or the presence of imaging artifact, this sign may not be detected and thus it is not very sensitive. It is, however, very specific when mimics such as arterial calcifications are excluded..$^{13,14}$ 
An objective way to evaluate the extent of ischemic changes and estimate patient prognosis is the widely used Alberta Stroke Program Early CT Scale system (ASPECTS), which was initially proposed in 2000 . The ASPECTS scale is a negative ordinal scale which assigns an equally weighted score of 1 to 10 to different MCA territory regions of interest on NCCT imaging. These regions include the caudate nucleus (C), insular ribbon (I), internal capsule (IC), lentiform nucleus ( $L)$, and 6 cortical MCA territory regions divided into superior and inferior anterior, middle, and posterior regions (M1-M6). These regions are assessed for early ischemic changes (EIC), which are defined as hypoattenuation or loss of gray-white differentiation. Isolated cerebral swelling without associated hypoattenuation is not considered an EIC because it may be seen with potentially viable parenchyma. ${ }^{15}$ A final ASPECTS score of 7 or less is associated with poorer prognosis due to a larger affected area. ${ }^{15}$ Some of the recent positive endovascular trials used ASPECTS as a selection criteria. A recent metaanalysis from the five thrombectomy trials in 2015 found a clear benefit of thrombectomy in patients with ASPECTS $>5 .{ }^{16}$ One such trial is the Thrombectomy Within 8 Hours after Symptom Onset in Ischemic Stroke (REVASCAT) which used a CT ASPECTS of $>7$ as a treatment cutoff. ${ }^{17}$ ASPECTS can also be evaluated on CT Angiography source images (CTA-SI) which are often obtained immediately following NCCT. CTA-SI can detect cerebral blood volume or flow abnormalities reflecting decreased perfusion which may not be able to be seen on NCCT. It has been suggested that CTA-SI ASPECTS is a better predictor for clinical outcomes and when compared to NCCT ASPECTS (Fig. 2) ${ }^{18}$ However, CTA-SI defined hypodensity is dependent on the CTA acquisition protocol and type of CT scanner. It is important to 
note that ASPECTS has limitations including moderately low intra-rater agreement. Furthermore, use of a single threshold to identify patients with poor outcome might lead to unjustified exclusion of patients from clinical trials or even treatment. There is active ongoing research to further evaluate the clinical use of ASPECTS and to apply it to different imaging modalities. ${ }^{15,19,20}$

\section{MRI Parenchymal Findings:}

MRI is more sensitive than NCCT in detecting AIS and hence an alternative to NCCT for acute stroke evaluation, provided it does not delay potential IV tPA or endovascular therapy. ${ }^{12,13} \mathrm{MRI}$ can detect intracranial hemorrhage with the same sensitivity as NCCT and can also provide information on the age of the bleed. ${ }^{12}$ In the hyperacute to acute phase, blood is typically T1 isointense and T2/FLAIR iso- to hyperintense. As intracellular methemoglobin content increases after the first 48 hours, T1 signal gradually increases. ${ }^{21}$ Chronic hemorrhages lose their $\mathrm{T} 1$ and $\mathrm{T} 2$ signal but are readily detectable with susceptibility weighted imaging as areas of signal dropout or blooming. Similar to the "dense vessel sign" on CT (Fig 3A), gradient echo (GRE) or susceptibilitity weighted images (SWI) on MRI can also help in visualizing the acute thrombus as an area of susceptibility or "blooming"(Fig. 3B). The presence of multiple cerebral microhemorrhages can sometimes pose a problem in clinical decision making. While patients with a few $(<5)$ microhemorrhages may not be at increased risk, recent literature suggests that patients with multiple $(>10)$ microhemorrhages are at increased risk for symptomatic ICH after thrombolytic therapy. Official recommendations for this scenario are still being established. ${ }^{12,21,22}$ 
Cytotoxic edema of acute infarct leads to decreased free diffusion of water, resulting in a decreased apparent diffusion coefficient (ADC) and increased signal on diffusion weighted imaging (DWI)(Fig. 3C, 3D, 4). DWI can detect an acute ischemic event within minutes and is an essential MRI sequence in acute stroke imaging. ${ }^{14}$ The area of diffusion restriction represents the "core" or irreversible injury which can expand over 24 hours if there is no reperfusion of potentially salvageable brain tissue. After the acute phase, vasogenic edema and cellular breakdown lead to an increase in extracellular water and a gradual increase in ADC signal over 9-11 days. ${ }^{14}$

Because diffusion restriction occurs very early following acute ischemic stroke, its presence can be used to estimate stroke timing. For example, a positive DWI and negative FLAIR, or DWI-FLAIR mismatch, can be used to determine that a stroke is within 4.5 hours of onset with an $83-87 \%$ positive predictive value. ${ }^{23}$ This is because the tissue damage which causes FLAIR abnormality has not yet occurred within that window. As shown in the Efficacy and Safety of MRI-based Thrombolysis in Wake-up Stroke (WAKE-UP) trial, the concept of DWI-FLAIR mismatch can be used to identify potential thrombolysis candidates when there is unknown symptom onset or a "wakeup" stroke. ${ }^{11}$

\section{Vascular imaging and Collateral Assessment:}

Non-invasive vascular imaging is now commonly used in the workup of AIS, particularly when endovascular therapy is contemplated. The recently positive endovascular trials used CTA as an imaging selection tool to identify patients with proximal anterior circulation occlusions..$^{4,5,6,7}$ The major goals of CTA are to identify proximal vessel 
occlusion, assess collateral circulation, and to aid in planning for endovascular treatment. ${ }^{24}$

Identification of large vessel occlusion (Fig. 5): Although a large percentage of patients with AIS $(19-39 \%)$ have no identifiable thrombus, those with thrombus have more severe strokes at baseline and are more likely to demonstrate large or proximal vessel occlusion, including ICA and MCA-M1 occlusions. ${ }^{8,25}$ In general, patients with longer, more proximal thrombi are more likely to benefit from endovascular thrombectomy and less likely to recanalize with IV tPA alone. ${ }^{25}$ The "clot burden score" was developed to address the difficulty of measuring precise thrombus length and to create a model for predicting outcome based on intracranial vessel involvement. The "clot burden score" starts with a score of 10 and subtracts points for involvement of certain vessels: 1 for infraclinoidal ICA, 2 for supraclinoidal ICA, 2 for proximal M1, 2 for distal M1, 1 for M2, and 1 for ACA (Fig. 5). A score of less than 10 was shown to be associated with reduced odds of long independent functional outcome with an odds ratio (OR) of as low as 0.09 for scores less than $5 .{ }^{26}$

CTA can also help in assessing collateral circulation, which can affect the rate of infarct growth. Patients with good collaterals generally can prevent irreversible infarction in susceptible brain parenchyma. ${ }^{8}$ Collateral grading can be used for therapeutic decision making even using a simple grading scale. In a post hoc analysis of the Randomized Trial of Intraarterial Treatment for Acute Ischemic Stoke (MR CLEAN) trial, collateral circulation was graded using four categories: grade 0 (no collaterals), grade 1 ( $<50 \%$ 
filling in the occluded territory), grade 2(50 to $100 \%$ filling in the occluded territory) and grade $3(100 \%$ filling). They demonstrated that patients with good collaterals (grade 3 ) had better response to intra-arterial therapy than patients with poor collaterals (Fig. 6) using the primary outcome of 90 day modified Rankin Scale scores ${ }^{4,27}$ Accurate collateral grading has been further enhanced with multiphase CTA (Fig. 7), which is performed by scanning from the aortic arch to the vertex in peak arterial phase followed by two sequential scans from the skull base to vertex in peak and late venous phases. This allows for temporal resolution which traditional single-phase CTA does not provide. $^{8}$

Finally, CTA can be useful in planning for endovascular therapy including evaluation of caliber and tortuosity of the intracranial and extracranial vessels, visualizing the ipsilateral carotid bifurcation, and to identify any variant anatomy. Information on additional pathology including stenosis, dissection, or aneurysm can all aid in device selection and access planning for intervention or alternative management. ${ }^{8}$

\section{Perfusion Imaging:}

The main goal of perfusion imaging is to discriminate between "penumbra" and the ischemic "core." The penumbra is defined as hypoperfused but potentially salvagable brain tissue. This is in contrast to the core which represents tissue that is irreversibly damaged. Because the penumbra can persist and the core can continue to enlarge beyond 12 hours from stroke onset, this discrimination can aid in clinical decision making even after the traditional acute endovascular treatment window of 6 hours. ${ }^{28}$ 
Both CT perfusion (CTP) and MRI perfusion weighted imaging (PWI) are accomplished by injecting a tracked bolus of IV contrast and serially imaging a volume of brain parenchyma during the injection. ${ }^{29}$ An advantage of CTP is that whole brain perfusion images can be obtained along with CTA using a single contrast bolus immediately following NCCT. ${ }^{30}$ Post-processing software is then used to calculate a variety of parameters based on the scan data and to generate perfusion maps. In the setting of CTP, the most commonly employed processing algorithm involves a deconvolution technique which takes into account variations in arterial inflow, venous outflow, and collateral circulation. ${ }^{29}$ The calculated maps for perfusion imaging include cerebral blood volume, cerebral blood flow, mean transit time (MTT) and time-to-max or time-topeak contrast concentration (Tmax)(Fig. 8). ${ }^{13,28}$

In general, critically hypoperfused tissue has a Tmax $>6$ seconds and has been validated in multiple studies. ${ }^{28,31}$ The mismatch between the total area of critically hypoperfused tissue and the ischemic core is used to estimate the penumbra (Fig 8). With MRI, the biggest advantage is that the ischemic core is reliably represented by the acutely infarcted area on DWI imaging. In contrast, core is indirectly estimated in CTP either using thresholds of CBV $<2-2.2 \mathrm{~g} / 100 \mathrm{ml}$ or more recently using decrease in CBF of $30-50 \%$ compared to normal tissue. ${ }^{29}$ This penumbra/core mismatch concept has been evaluated as a selection criteria in several clinical trials. In the Diffusion Weighted Imaging Evaluation for Understanding Stroke Evolution Study-2 (DEFUSE 2) trial, a group of patients who underwent endovascular reperfusion within 12 hours of stroke onset were evaluated for "Target Mismatch"; criteria included a ratio of critically hypoperfused tissue to ischemic core $\geq 1.8$, an ischemic core $<70 \mathrm{ml}$, and less than 
$100 \mathrm{ml}$ of total tissue with $\operatorname{Tmax}>10$ seconds. They demonstrated that patients who met Target Mismatch criteria had more favorable clinical outcomes and less infarct growth following endovascular reperfusion when compared to patients who did not meet the criteria. ${ }^{31}$ The Endovascular Therapy for Ischemic Stroke With Perfusion-Imaging Selection (EXTEND IA) trial which used CTP for all patients required evidence of salvageable tissue and excluded patients with a large ischemic core $>70 \mathrm{~mL} .{ }^{6}$ The Stent-Retriever Thrombectomy after Intravenous tPA vs. t-PA Alone in Stroke (SWIFT PRIME) trial excluded patients with a core $>50 \mathrm{~mL}$ or patients with $>100 \mathrm{ml}$ brain tissue with t-max $>10$ seconds $^{7}$ Early results from the recent Clinical Mismatch in the Triage of Wake-up and Late Presenting Strokes Undergoing Neurointervention with Trevo (DAWN) trial, which also used perfusion as a selection tool, demonstrated that endovascular treatment up to 24 hours of stroke onset significantly decreased poststroke disability and improved functional independence at 90 days when compared to medical management alone..$^{9,10}$

Some of the disadvantages of CTP is lack of whole brain coverage and lack of standardization. However, newer scanners are capable of large areas of coverage. Using fully automated software for post-processing of CTP is ideal and allows efficiency, standardization of processing methodology and perfusion map appearance, and can also be compared easily in multicenter trials. Trials such as EXTEND-IA, SWIFT PRIME and DAWN have demonstrated the feasibility of modern CTP with standardized automated processing and their use in triaging patients with acute ischemic stroke. .,7,9 $^{-1}$ 


\section{AHA Recommendations for Imaging in Acute Stroke:}

According to the American Heart Association guidelines, emergency imaging of the brain, most commonly NCCT, is recommended before any specific treatment for acute stroke is initiated (Class I; Level of Evidence A). If endovascular therapy is contemplated, a noninvasive intracranial vascular study is strongly recommended but should not delay intravenous r-tPA if indicated. (Class I; Level of Evidence A). This is a new recommendation in the 2015 update based on the multiple endovascular trials. ${ }^{32}$ Benefits of perfusion studies remain unknown (Class IIb; Level of Evidence C). ${ }^{31}$ Further randomized controlled trials may be helpful to determine whether advanced imaging paradigms with perfusion or angiographic imaging are beneficial for selecting patients within 6 hours of symptom onset and with an ASPECTS $<6$. Also, according to AHA guidelines, further randomized, controlled trials should be done to determine whether advanced imaging paradigms with CT or MR perfusion are beneficial for selecting patients for acute reperfusion therapy who are beyond 6 hours from symptom onset. ${ }^{31}$ However, the rapidly changing landscape of acute stroke treatment including the recent DAWN results may prompt additional AHA updates on imaging requirements of patient subgroup beyond 6 hours. $^{9}$

\section{Optimizing Imaging Workflow:}

Time is of essense in management of an acute stroke patient as "Time is Brain". Approximately 1.9 million neurons are destroyed every minute in the territory of occluded artery. ${ }^{33}$ Early reperfusion is a critical factor for good outcomes. As imaging is an integral part of the workup, all imaging needs to be performed and interpreted in a 
timely, efficient manner. Thus, important aspects of the stroke workflow center around the imaging department such as patient triaging, image acquisition, image interpretation and decision making. ${ }^{34}$ Although the imaging paradigms may be slightly different in different institutions, it is important to remember that any imaging including CTA or CTP should not introduce delays in treatment. Parallel processes in the stroke workflow should be encouraged. For example, IV tPA can be started in the scanner as a CTA/CTP is being performed. Delaying a CTA for availability of renal function tests is suboptimal. Studies have shown that there is no significant difference in the incidence of acute renal injury between contrast enhanced and non-enhanced CT scans, irrespective of the baseline renal function. ${ }^{35}$

Time metrics are also important for interpretation of the imaging studies. The"Get with

Guidelines"recommends that non contrast head CT in suspected acute stroke should be obtained within 25 min of admission to the emergency department and that these scans be interpreted within 20 min of being obtained. Ideally, patient should be transferred from "Door-to- Scanner", by-passing the Emergency department and saving time. Multidisciplinary teamwork and standardized institutional protocols contribute to improved times to treat and in turn improved functional outcome. ${ }^{36}$ It is critical that the radiologist is an integral part of this team to optimize imaging work up of AIS patients.

\section{Pediatric Stroke:}

There is increasing recognition of the occurrence of ischemic stroke in children. Currently reported annual incidence of pediatric arterial ischemic stroke in North 
America is between 2-3 per 100,000 children, which is much lower than the incidence in adults. ${ }^{37}$ However, this incidence of pediatric stroke is likely underreported because of lack of accurate diagnosis. ${ }^{38}$ Ischemic stroke in children may be due to arterial or venous ischemia, and can include neonatal/perinatal stroke, childhood ischemic stroke and stroke in the adolescent and young adult.

Childhood AIS has distinct risk factors compared to adult stroke. Unlike adults, atherosclerotic disease is rare in children. In a large series of children with arterial ischemic stroke (AIS) studied by the international pediatric stroke study (IPSS), approximately $90 \%$ had at least one risk factor identified, such as vasculitis (Fig. 9). ${ }^{39,40}$ Childhood AIS can lead to permanent neurological deficits in approximately three fourths of the cases, and lead to death in $10 \%$ of cases. ${ }^{41,42}$. Approximately $20 \%$ of children with arterial ischemic strokes can suffer recurrences within five years. ${ }^{41}$

In many children with stroke, imaging, and accurate diagnosis may be delayed due to lack of clinical suspicion. ${ }^{38}$ Presenting symptoms of childhood stroke can be misdiagnosed as seizure, altered mental status, lethargy or headache due to lack of awareness by families and medical providers. ${ }^{39}$ Additionally, there are many stroke mimics in the pediatric population including metabolic encephalopathy with stroke-like symptoms (MELAS), posterior reversible encephalopathy syndrome (PRES), or other toxic and metabolic abnormalities.

Many factors determine the imaging study that is eventually performed when there is a suspicion of stroke in children. The age of the patient is important as children younger than four years of age are generally unable to hold still for an MRI. As some imaging 
centers may not have MRI technologists in-house at all times, after hours presentation could be another factor to consider. Nevertheless, early imaging is key. A non-contrast head CT followed by contrast enhanced CTA of the head and neck would be the best initial work up if an emergent MRI cannot be performed due to availability or contraindication. ${ }^{43}$ As always, the risk of ionizing radiation should be considered in children and should be weighed against the benefits of emergent CT imaging. ${ }^{44,45,46}$ Non-contrast MR perfusion methods using arterial spin labelling ASL have shown comparable sensitive to gadolinium-based perfusion in identifying the perfusion defect in childhood AIS (Fig. 9C). Recently, gadolinium deposition in the brain have been shown after cumulative doses of linear gadolinium contrast agents. ${ }^{47,}$ Thus, noncontrast MR perfusion methods such as arterial spin labelled (ASL) are used more frequently in the pediatric population..$^{48}$ Susceptibility weighted imaging (SWI) is also a promising tool in childhood AIS, with mismatch of diffusion and hypointense venous SWI signal predicting stroke progression. ${ }^{49} \mathrm{SWI}$ reflects blood oxygenation levels, and SWI values in the veins can provide an alternative assessment of degree of brain perfusion and the perfusion-diffusion mismatch.

Vessel wall imaging (Fig. 9E) is a relatively new MR technique that can give detailed information regarding vessel wall thickening, luminal narrowing and enhancement; assessing among other things the presence of arterial inflammation. It holds promise in the decision making process of Childhood AIS, particularly when an arteriopathy such as vasculitis, is suspected. ${ }^{50}$ Findings that would suggest arteriopathy include, dissection, arterial banding, luminal narrowing, wall irregularity, beading, ectasia, aneurysm or pseudoaneurysm. ${ }^{51}$ 
Childhood stroke is usually treated conservatively, with no established benefit of endovascular therapy.

\section{Future Directions and Ongoing Trials:}

Future directions in acute ischemic stroke imaging include continuing to improve outcomes by early recognition, streamlined workflow, and appropriate triage. Areas of inquiry will be in the development and application of rapid, reliable imaging techniques and standardization of protocols with a focus on image quality and quantification. Additionally, there are continued efforts to expand treatment windows.

Some of the trials spearheading these advances include the recently positive DAWN trial $^{9,10}$ Additional ongoing studies include a Study of Intravenous Thrombolysis With Alteplase in MRI-Selected Patients (MR WITNESS), where MR findings of acute stroke are used to initiate intravenous tPA within 4.5 hours of stroke onset (NCT01282242). The Diffusion Weighted Imaging Evaluation for Understanding Stroke Evolution Study-3 (DEFUSE 3) trial which was focusing on anterior circulation stroke presenting 6-16 hours after onset was recently halted after interim analysis. ${ }^{52}$ Eligibility was based on presence of proximal occlusion and target mismatch profile on MR or CT perfusion calculated and the results are expected in the near future (NCT02586415). Perfusion Imaging Selection of Ischemic Stroke Patients for Endovascular Therapy (POSITIVE) stroke trial is an ongoing trial assessing the benefit of endovascular treatment versus medical management in late presenting strokes 6-12 hours after onset (NCT01852201). Other stroke trials are testing the use of intravenous tPA in late presenting strokes (4.5 
to 9 hours) such as the European Cooperative Acute Stroke Study (ECASS)-IV. ${ }^{8}$ The key points from the major trials we have discussed are outlined in Table 1.

\begin{tabular}{|c|c|c|c|c|c|c|c|c|}
\hline Trial & MR CLEAN & EXTEND IA & SWIFT PRIME & WAKE UP & REVASCAT & ESCAPE & DEFUSE 3 & DAWN \\
\hline $\begin{array}{l}\text { Primary } \\
\text { Imaging } \\
\text { Modalities }\end{array}$ & $\begin{array}{l}\text { NCCT + CTA, } \\
\text { MRA, or DSA }\end{array}$ & NCCT, CTP & NCCT, CTP & MRI & $\mathrm{NCCT}, \mathrm{MRI}$ & $\begin{array}{l}\text { NCCT, CTA } \\
\text { (multiphasic) }\end{array}$ & $\begin{array}{l}\text { CTA, CTP, MRI, } \\
\text { MRA }\end{array}$ & $\begin{array}{l}\text { NCCT, MRI } \\
\text { MRA, CTP, CTA }\end{array}$ \\
\hline $\begin{array}{l}\text { Treatment } \\
\text { Window }\end{array}$ & $<6$ hours & $<4.5$ hours & $<6$ hours & $\begin{array}{l}<4.5 \mathrm{hrs} \text {. after } \\
\text { symptom } \\
\text { recognition }\end{array}$ & $<8$ hours & $<12$ hours & $6-16$ hours & $6-24$ hours \\
\hline $\begin{array}{l}\text { Main } \\
\text { Imaging } \\
\text { Criteria }\end{array}$ & $\begin{array}{l}\text { Proximal } \\
\text { occlusion }\end{array}$ & $\begin{array}{l}\text { Proximal } \\
\text { occlusion, Core } \\
<70 \mathrm{ml}\end{array}$ & $\begin{array}{l}\text { Proximal } \\
\text { occlusion, Core } \\
<50 \mathrm{ml}\end{array}$ & $\begin{array}{l}\text { DWI - FLAIR } \\
\text { Mismatch }\end{array}$ & $\begin{array}{l}\text { Proximal } \\
\text { occlusion, CT } \\
\text { ASPECTS } \geq 7 \text { or } \\
\text { DWI ASPECTS } \geq \\
6\end{array}$ & $\begin{array}{l}\text { ASPECTS }>6, \\
\text { moderate to } \\
\text { good } \\
\text { collaterals, } \\
\text { proximal } \\
\text { occlusion }\end{array}$ & $\begin{array}{l}\text { Target } \\
\text { Mismatch } \\
\text { Profile (core < } \\
70 \mathrm{ml} \text {, } \\
\text { mismatch ratio } \\
>1.8 \text { and } \\
\text { mismatch vol. } \\
>15 \mathrm{ml} \text { ) }\end{array}$ & $\begin{array}{l}\text { Clinical } \\
\text { Imaging } \\
\text { Mismatch } \\
\text { (core < } 21 \mathrm{ml} \text {, } \\
31 \mathrm{ml} \text {, or } 51 \mathrm{ml} \\
\text { depending on } \\
\text { age and NIHSS) }\end{array}$ \\
\hline Intervention & $\begin{array}{l}\text { Intra-arterial } \\
\text { Therapy vs } \\
\text { Standard Care }\end{array}$ & $\begin{array}{l}\text { Thrombectomy } \\
\text { vs Standard } \\
\text { Care }\end{array}$ & $\begin{array}{l}\text { Thrombectomy } \\
\text { vs Standard } \\
\text { Care }\end{array}$ & IV tPA vs None & $\begin{array}{l}\text { Thrombectomy } \\
\text { vs Standard } \\
\text { Care }\end{array}$ & $\begin{array}{l}\text { Thrombectomy } \\
\text { vs Standard } \\
\text { Care }\end{array}$ & $\begin{array}{l}\text { Thrombectomy } \\
\text { vs. Standard } \\
\text { Care }\end{array}$ & $\begin{array}{l}\text { Thrombectomy } \\
\text { vs Standard } \\
\text { care }\end{array}$ \\
\hline $\begin{array}{l}\text { Primary } \\
\text { Clinical } \\
\text { Outcome }\end{array}$ & $\begin{array}{l}90 \text { Day modified } \\
\text { Rankin Score }\end{array}$ & $\begin{array}{l}\text { 24-Hour } \\
\text { reperfusion }\end{array}$ & $\begin{array}{l}90 \text { day } \\
\text { modified } \\
\text { Rankin Score }\end{array}$ & $\begin{array}{l}90 \text { day } \\
\text { modified } \\
\text { Rankin Score }\end{array}$ & $\begin{array}{l}90 \text { day } \\
\text { modified } \\
\text { Rankin Score }\end{array}$ & $\begin{array}{l}90 \text { day } \\
\text { modified } \\
\text { Rankin Score }\end{array}$ & $\begin{array}{l}90 \text { day } \\
\text { modified } \\
\text { Rankin Score }\end{array}$ & $\begin{array}{l}90 \text { day } \\
\text { modified } \\
\text { Rankin Score }\end{array}$ \\
\hline Comment & $\begin{array}{l}\text { Benefit of intra } \\
\text { arterial therapy. } \\
\text { Better outcomes } \\
\text { with good } \\
\text { collaterals on } \\
\text { CTA }\end{array}$ & $\begin{array}{l}\text { CTP for patient } \\
\text { selection. } \\
\text { Benefit of early } \\
\text { endovascular } \\
\text { treatment. }\end{array}$ & $\begin{array}{l}\text { CTP for patient } \\
\text { selection. } \\
\text { Benefit of early } \\
\text { endovascular } \\
\text { treatment. }\end{array}$ & $\begin{array}{l}\text { Can use MRI to } \\
\text { determine } \\
\text { stroke age < } \\
4.5 \text { hours }\end{array}$ & $\begin{array}{l}\text { Extended } \\
\text { endovascular } \\
\text { treatment } \\
\text { window to } 8 \\
\text { hours }\end{array}$ & $\begin{array}{l}\text { Extended } \\
\text { endovascular } \\
\text { treatment } \\
\text { window to } 12 \\
\text { hours }\end{array}$ & $\begin{array}{l}\text { Extended } \\
\text { treatment } \\
\text { window to 6- } \\
24 \text { hours with } \\
\text { appropriate } \\
\text { mismatch }\end{array}$ & $\begin{array}{l}\text { Extended } \\
\text { treatment } \\
\text { window to } 24 \\
\text { hours with } \\
\text { appropriate } \\
\text { mismatch }\end{array}$ \\
\hline
\end{tabular}

Table 1. 


\section{Conclusion:}

Rapid multimodal imaging is essential as soon as acute ischemic stroke is suspected. Initial NCCT or MRI is critical to identify contraindications to IV TPA and evaluate the extent of the infarct. Objective scoring systems such as ASPECTS and ASPECTSbased thresholds are commonly used for treatment triage. Vessel based imaging is additionally performed to identify patients with large proximal vessel occlusions who are candidates for endovascular therapy or treatment in extended time windows. Using perfusion imaging, new endovascular stroke trials such as DAWN trial have extended the stroke treatment time window up to 24 hours after stroke onset. Because the imaging criteria for treatment candidates continue to evolve, it is critical for radiology departments to understand current recommendations and guidelines in order to make appropriate adjustments to their workflow. This also requires collaboration and coordination with other providers including the prehospital EMS, emergency department, stroke neurologists, and neuro-interventionalists. The subgroup of pediatric stroke is rare, nevertheless important, would need high index of suspicion as the presentation and etiology is different from adults. Many of the imaging based selection criteria for extending treatment windows is soon becoming standard of care and may be reflected in future national guidelines. These exciting changes will pave the way for future stroke research and management to improve stroke outcomes.

\section{References:}

1. Liebeskind DS: Collateral circulation. Stroke 34(9): 2279-84, 2003 
2. Emberson J, Lees KR, Lyden P, et al: Effect of treatment delay, age, and stroke severity on the effects of intravenous thrombolysis with alteplase for acute ischaemic stroke: a meta-analysis of individual patient data from randomised trials. Lancet 384(9958): 1929-35, 2014

3. Mishra SM, Dykeman J, Sajobi TT, et al: Early reperfusion rates with IV tPA are determined by CTA clot characteristics. Am J Neuroradiol 35(12): 2265-72, 2014

4. Berkhemer OA, Fransen PSS, Beumer D, et al: A randomized trial of intraarterial treatment for acute ischemic stroke. N Engl J Med 372: 11-20, 2015

5. Goyal M, Demchuk AM, Menon BK, et al: Randomized assessment of rapid endovascular treatment of ischemic stroke. N Engl J Med 372(11): 1019-30, 2015

6. Campbell BCV, Mitchell PJ, Kleinig TJ, et al: Endovascular therapy for ischemic stroke with perfusion imaging selection. N Eng J Med 372: 1009-18, 2015

7. Saver JL, Jahan R, Jovin TG, et al: Solitaire flow restoration device versus the Merci Retriever in patients with acute ischaemic stroke (SWIFT): a randomised, parallel-group, non-inferiority trial. Lancet 380(9849): 1241-9, 2012

8. Menon BK, Campbell BC, Levi C, et al: Role of vascular imaging in current acute ischemic stroke workflow for endovascular therapy. Stroke 46(6): 1453-61, 2015

9. Jovin TG, Saver JL, Ribo M, et al: Diffusion-weighted imaging or computerized tomography perfusion assessment with clinical mismatch in the triage of wake up and late presenting strokes undergoing neurointervention with Trevo (DAWN) trial methods. Int J Stroke 12(6): 641-652, 2017 
10. Caso V, van der Worp B, Fischer U: European Stroke Organizational Report. Stroke 48: e195-e196, 2017

11. Thomalla G, Boutitie F, Fiebach JB, et al: Stroke With Unknown Time of Symptom Onset: Baseline Clinical and Magnetic Resonance Imaging Data of the First Thousand Patients in WAKE-UP (Efficacy and Safety of MRI-Based Thrombolysis in Wake-Up Stroke: A Randomized, Doubleblind, PlaceboControlled Trial). Stroke 48(3): 770-773, 2017

12. Latchaw RE, Alberts MJ, Lev MH, et al: Recommendations for imaging of acute ischemic stroke. Stroke 40 (11): 3646-3678, 2009

13. Srinivasan A, Goyal M, Azri FA, et al: State-Of-The-Art imaging of acute stroke. Radiographics 26: S75-S95, 2006

14. Muir KW, Buchan A, von Kummer R, et al: Imaging of acute stroke. Lancet Neurology 5(9): 755-68, 2006

15. Puetz V, Dzialowski I, Hill MD, et al: The Alberta Stroke Program Early CT Score in clinical practice: What have we learned. International Journal of Stroke 4(5): 354-364, 2009

16. Goyal M, Menon BK, van Zwan WH, et al: Endovascular thrombectomy after large-vessel ischemic stroke: a meta-analysis of individual patient data from five randomised trials. Lancet 387 (10029): 1723 - 1732, 2016

17. Tudor GJ, Chamorro A, Cobo E, et al: Thrombectomy within 8 hours after symptoms onset in ischemic stroke. NEJM 372: 2296-2306, 2015 
18. Bhatia R, Bal SS, Shobha N, et al: CT Angiographic source images predict outcome and final infarct volume better than noncontrast CT in proximal vascular occlusions. Stroke 42: 1575-1580, 2011

19. Schroder J, Thomalla G: A critical review of Alberta Stroke Program Early CT Score for evaluation of acute stroke imaging. Frontiers in Neurology 7: 245, 2017

20. Farzin B, Fahed R, Guilbert F, et al: Early CT changes in patients admitted for thrombectomy: Intrarater and interrater agreement. Neurology 87(3): 249-56, 2016

21. Kidwell CS, Wintermark M: Imaging of intracranial haemorrhage. Lancet Neurology 7(3): 256-67, 2008

22. Tsivgoulis G, Zand R, Katsanos AH: Risk of symptomatic intracranial hemorrhage after intravenous thrombolysis in patients with acute ischemic stroke and high microbleed burden. JAMA Neurology 73(6): 675-683, 2016

23. Odland A, Saervoll P, Advani R, et al: Are current MRI criteria using the DWIFLAIR mismatch concept for selection of patients with wake-up stroke to thrombolysis excluding too many patients? Scand J Trauma Resusc Emerg Med 23: 22,2015

24. Goyal M, Derdeyd CP, Fiorella D, et al: Recent endovascular trials: implications for radiology departments, radiology residency, and reuroradiology fellowship training at comprehensive stroke centers. Radiology 278(3): 642-45, 2016

25. Qazi E, Al-Ajlan FS, NAjm M, et al: The role of vascular imaging in the initial assessment of patients with acute ischemic stroke. Curr Neurol Neurosci Rep 16(4): 32, 2016 
26. Puetz V, Dzialowski I, Hill MD, et al: intracranial thrombus extent predicts clinical outcome, final infarct size and hemorrhagic transformation in ischemic stroke: the Clot Burden Score. International Journal Of Stroke 3(4): 230-236, 2008

27. Berkhemer OA, Jansen IGH, Beumer D, et al: Collateral status on baseline computed tomographic angiography and intra-arterial treatment effect in patients with proximal anterior circulation stroke. Stroke 47(3): 768-76, 2016

28. Paciaroni M, Caso V, Agnelli G: The concept of ischemic penumbra in acute stroke and therapeutic opportunities. European Neurology 61(6): 321-30, 2009

29. Heit JJ, Wintermark M: Perfusion computed tomography for the evaluation of acute ischemic stroke. Stroke 47(4): 1153-8, 2016

30. Frolik A, Psychogios MN, Klotz E, et al: Angiographic reconstructions from whole-brain perfusion CT for the detection of large vessel occlusion in acute stroke. Stroke 43(1): 97-102, 2011

31. Lansberg MG, Straka M, Kemp S, et al: Magnetic Resonance Imaging profile and response to endovascular reperfusion: results of the DEFUSE 2 prospective cohort Study. Lancet Neurology 11(10): 860-867, 2012

32. Powers WJ, Derdeyn CP, Biller J, et al: 2015 American Heart Association/American Stroke Association focused update of the 2013 guidelines for the early management of patients with acute ischemic stroke regarding endovascular treatment. Stroke 46: 3020-3025, 2015

33. Saver JL: Time is brain - quantified. Stroke 37: 263-266, 2006

34. Assis ZA, Menon BK, Goyal M: Imaging department organization in a stroke center and workflow processes in acute stroke. Eur J Radiol. In Press, 2017 
35. McDonald JR, McDonald JS, Bida PJ et al: Intravenous contrast materialinduced nephropathy: causal or coincident phenomenon? Radiology 267(1): 106-118, 2013

36.Zerna C, Assis ZA, d'Esterre CD, et al: Imaging, Intervention, and Workflow in Acute Ischemic Stroke: The Calgary Approach. American Journal of Neuroradiology 37 (6): 978-984, 2016

37. Agrawal N, Johnston SC, Wu YW, et al: Imaging data reveal a higher pediatric stroke incidence than prior US estimates. Stroke 40(11): 3415-21, 2009

38. Rafay MF, Pontigon AM, Chiang J, et al: Delay to diagnosis in acute pediatric arterial ischemic stroke. Stroke 40(1): 58-64, 2009

39. Mackay MT, Wiznitzer M, Benedict SL, et al: Arterial ischemic stroke risk factors: the International Pediatric Stroke Study. Ann Neurol 69(1): 130-40, 2011

40. Amlie-Lefond C, Bernard TJ, Sebire G, et al: Predictors of cerebral arteriopathy in children with arterial ischemic stroke: results of the International Pediatric Stroke Study. Circulation 119(10): 1417-23, 2009

41. Fullerton HJ, Wu YW, Sidney S, et al: Risk of recurrent childhood arterial ischemic stroke in a population-based cohort: the importance of cerebrovascular imaging. Pediatrics, 119(3): 495-501, 2007

42. De Schryver EL, Kappelle LJ, Jennekens-Schinkel A, et al: Prognosis of ischemic stroke in childhood: a long-term follow-up study. Dev Med Child Neurol 242(5): $313-8,2000$

43. Yock-Corrales A, Barnett $P$ : The role of imaging studies for evaluation of stroke in children. Pediatr Emerg Care 27(10): 966-74; quiz 975-7, 2011 
44. Mathews JD, Forsythe AV, Brady Z, et al: Cancer risk in 680,000 people exposed to computed tomography scans in childhood or adolescence: data linkage study of 11 million Australians. BMJ 346: f2360, 2013

45. Boutis K, Cogollo W, Fischer J, et al: Parental knowledge of potential cancer risks from exposure to computed tomography. Pediatrics 132(2): 305-11, 2013

46. Pearce MS, Salotti JA, Little MP, et al: Radiation exposure from CT scans in childhood and subsequent risk of leukaemia and brain tumours: a retrospective cohort study. Lancet 380(9840): 499-505, 2012

47. Flood TF, Stence NV, Maloney JA, et al: Pediatric Brain: Repeated Exposure to Linear Gadolinium-based Contrast Material Is Associated with Increased Signal Intensity at Unenhanced T1-weighted MR Imaging. Radiology 282(1): 222-228, 2017

48. Chen J, Licht DJ, Smith SE, et al: Arterial spin labeling perfusion MRI in pediatric arterial ischemic stroke: initial experiences. J Magn Reson Imaging 29 (2): 28290,2009

49. Polan RM, Poretti A, Huisman TAGM et al: Susceptibility-Weighted Imaging in Pediatric Arterial Ischemic Stroke: A Valuable Alternative for the Noninvasive Evaluation of Altered Cerebral Hemodynamics Am J Neuroradiol 36 (4) 783-788, 2015

50. Obusez EC, Hui F, Hajj-ali RA, et al: High-resolution MRI vessel wall imaging: spatial and temporal patterns of reversible cerebral vasoconstriction syndrome and central nervous system vasculitis. Am J Neuroradiol 35(8) 1527-32, 2014 
51. Wintermark M, Hills NK, deVeber GA, et al: Arteriopathy diagnosis in childhood arterial ischemic stroke: results of the vascular effects of infection in pediatric stroke study. Stroke 45 (12): 3597-605, 2014

52. Griessenauer CJ, Schirmer CM: Dawn of an even newer era: mechanical thrombectomy for acute ischemic stroke beyond 6 to 8 hours. World Neurosurgery 104: 968-969, 2017 
Figure Legends:

Table 1. Key points from recent and ongoing stroke trials. $4,5,6,7,9,11,17,52$ "Standard Care" is defined as administration of IV tPA within 4.5 hours of stroke onset if there are no contraindications. In the treatment arms, IV tPA was not withheld if indicated. "Proximal Occlusion" is defined as a large anterior circulation vessel occlusion.Figure 1. CT Parenchymal and Vascular Findings in Acute Stroke. 45 year old male with right sided weakness, 5 hours since last known prior. Axial non-contrast CT images (A, B, C) demonstrate hypoattenuation and loss of gray-white differentiation in the left MCA distribution with involvement of the internal capsule, lentiform nuclei, and insular cortex (arrows on A, B). There is a left "hyperdense vessel" sign (bold arrow on C) indicative of left M1 thrombus. Axial CT Angiography image (D) confirmed the occlusive thrombus (arrow).

Figure 2. Non-contrast CT (NCCT) and CT-Angiography Source Images (CTA-SI) ASPECTS. Patient presented with right-sided weakness and concern for acute stroke. Initial NCCT (A, B) demonstrates no signs of ischemia, ASPECTS score $=0$. CTA Source Images (CTA-SI) obtained 11 minutes later $(C, D)$ demonstrate a large left MCA territory stroke with ASPECTS score $=2$, sparing only the internal capsule and head of the caudate.

Figure 3. MRI Findings in acute ischemic stroke. 84 year-old lady who presented with dysarthria. Initial NCCT demonstrates a tiny left "MCA dot sign" (arrow) with hypoattenuation in the adjacent insular cortex $(A)$. Subsequent MRI (B) shows a "blooming thrombus" on susceptibility weighted imaging (arrow on B). Corresponding DWI (C) and ADC map (D) confirm area of restricted diffusion consistent with an acute infarct in this territory.

Figure 4: Acute Infarct on Diffusion-Weigthed Imaging (DWI). Patient with left sided weakness. A large area of diffusion restriction on DWI (A) and ADC (B) images is consistent with acute right MCA territory infarct with mild mass effect on the right lateral ventricle.

Figure 5: Vascular Imaging and Endovascular Therapy on Acute Ischemic Stroke. Axial CT angiography (A) showing an occluded right MCA (arrow) with moderate collateral circulation. Right MCA thrombus on 3D reconstruction images (B) (bold arrow). Pre- (C) and post- (D) mechanical thrombectomy digital subtraction angiography images show successful reperfusion of the right MCA (arrows on C and D).

Figure 6: Moderate Collaterals on CT-Angiography. Multiphasic CTA in a patient with mild right MCA stenosis. Images were obtained in arterial (A), mid venous (B), and delayed venous $(C)$ phases and demonstrate sluggish, delayed filling of right sided collateral vessels (arrows).

Figure 7: Poor Collaterals on CT-Angiography. A patient with a large left MCA territory infarct demonstrates absent collaterals (arrows) on frontal CTA (A). The patient 
was ineligible for endovascular therapy and subsequently required decompressive craniotomy (B).

Figure 8: CT Perfusion in Acute Ischemia. Post-processed CT perfusion images from a patient with an acute right MCA territory infarct. The images in (A) show NCCT and perfusion maps, from left to right, of cerebral blood volume (CBV), cerebral blood flow (CBF), mean transit time (MTT) and time to maximum (Tmax). The perfusion maps are color coded with darker areas on the CBV and CBF maps representing decreased blood volume and perfusion. The MTT and Tmax maps have color coded scales. For example, blue areas on the Tmax map represent areas of Tmax between 4 and 6 seconds while red areas represent Tmax $>10$ seconds. The core (B) was estimated using threshold of CBF of 0.3 (arrows on $\mathrm{B}$ ). The penumbral volumes (C) were calculated using Tmax $>6$ sec. (arrows on $C$ ).

Figure 9: Probable Vasculitis on Pediatric Stroke. 4 year old girl presenting with acute stroke. FLAIR (A) image with hyperintensity in the left basal ganglia (arrow on A). $A D C$ maps $(B)$ demonstrate true diffusion restriction consistent with acute infarct. pCASL flow images (C) demonstrate decreased flow in the left basal ganglia (arrow). MIP images from MR angiogram (D) demonstrates narrowing of the distal left internal carotid artery and proximal MCA and ACA (bold arrow). T1 post contrast imaging of the vessel wall $(E)$ demonstrates diffuse asymmetric enhancement of the left petrous internal carotid artery (arrow on E) suggesting vasculitis. 


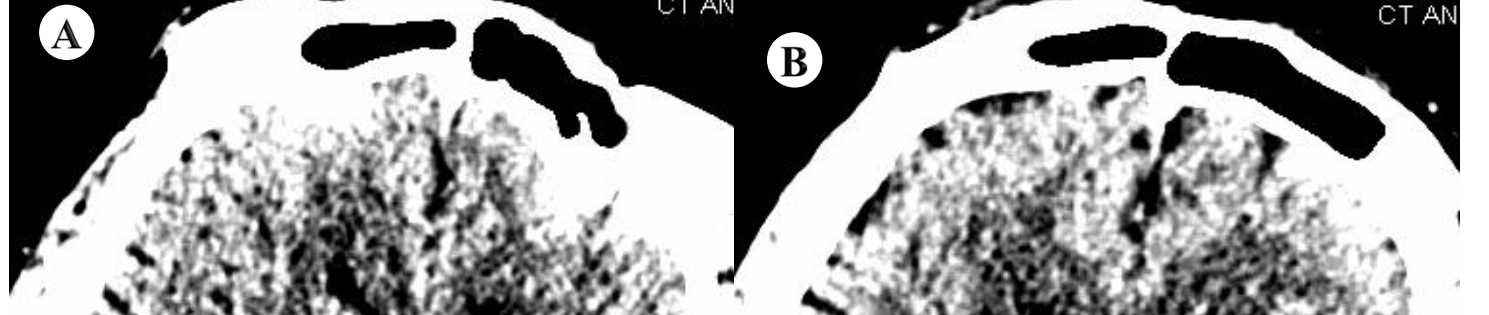
$*$
4

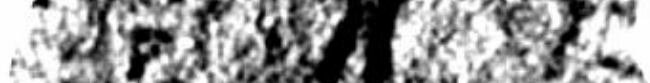

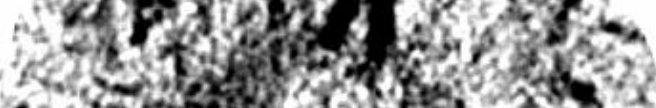

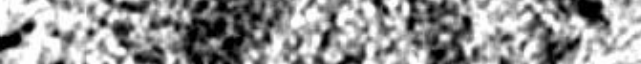

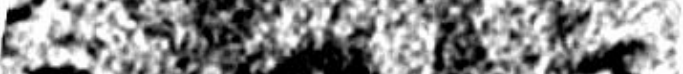
crits.

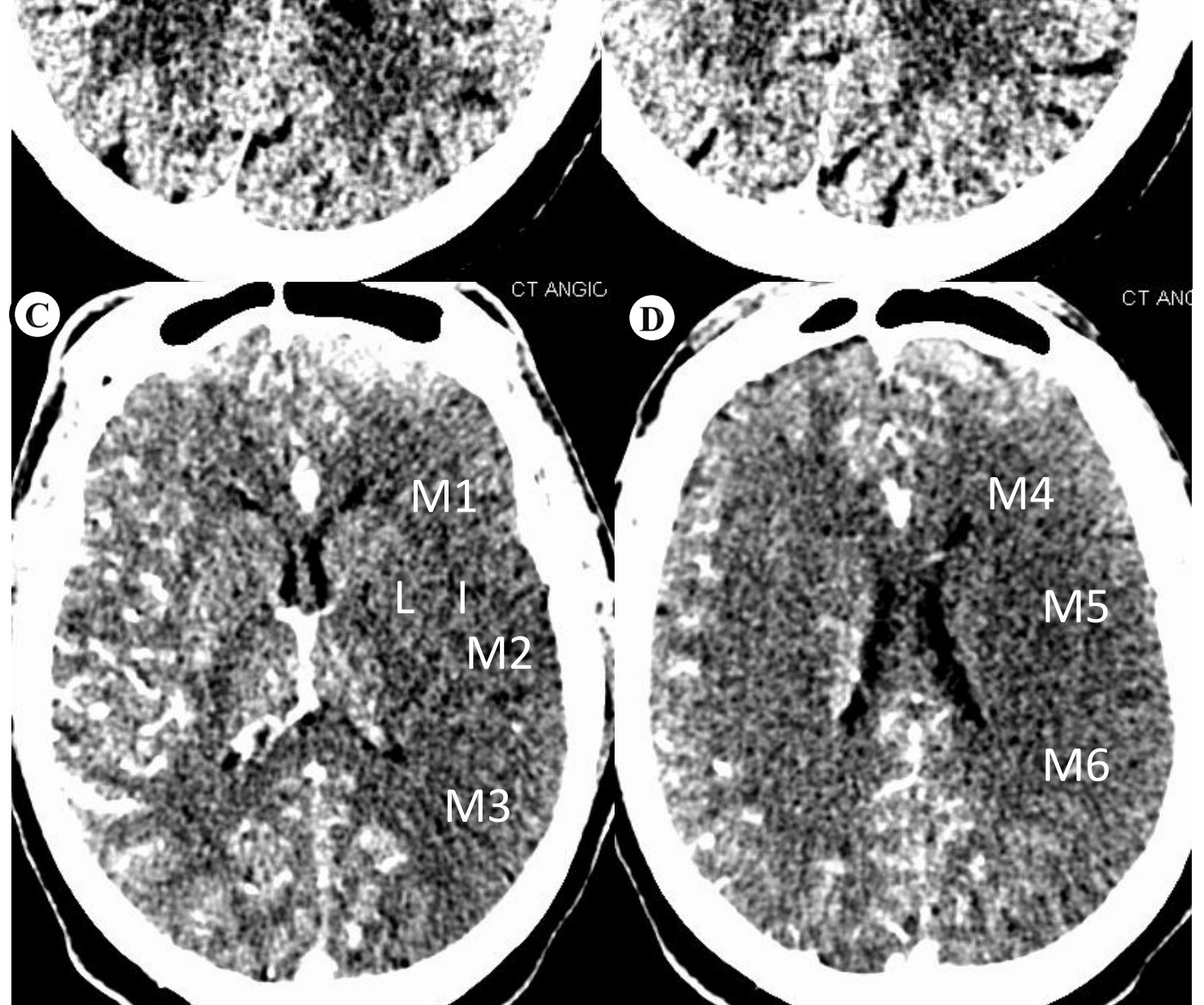

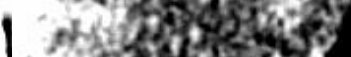

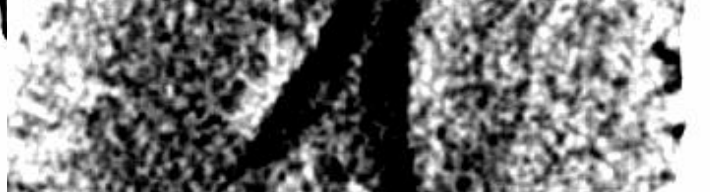
wos

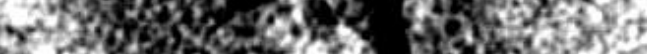

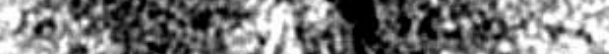

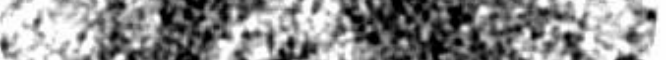
3.

(D) 


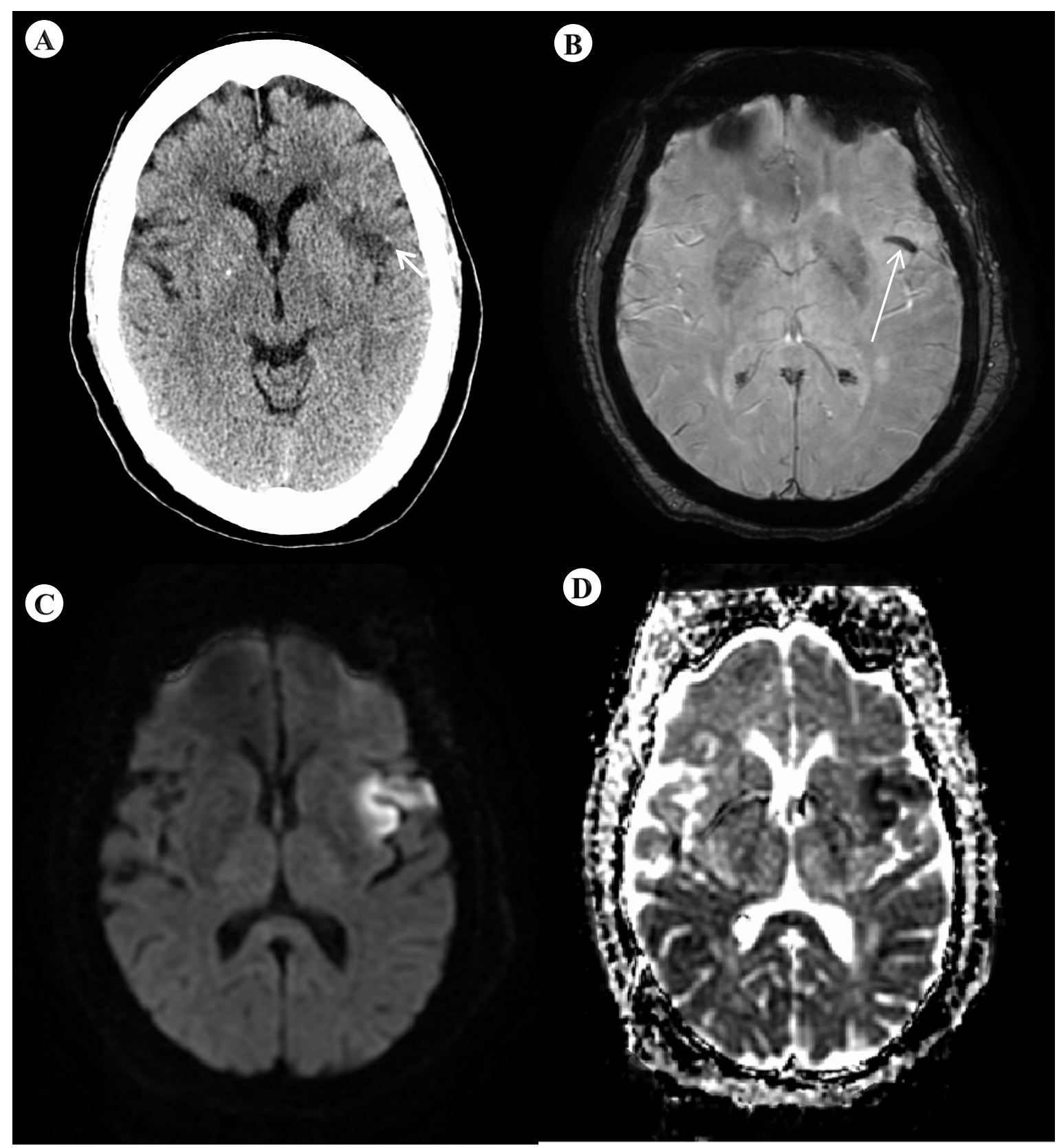




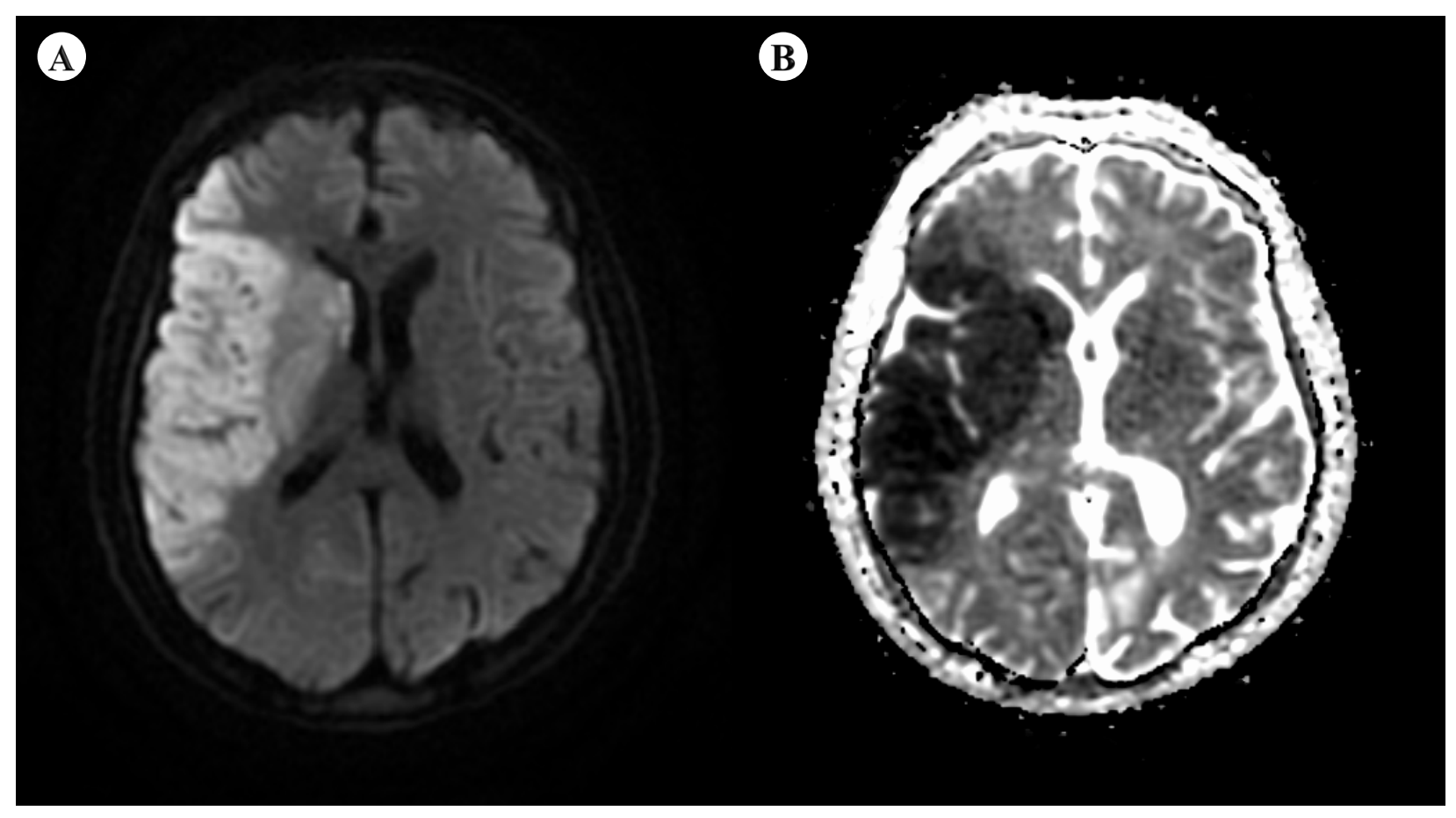




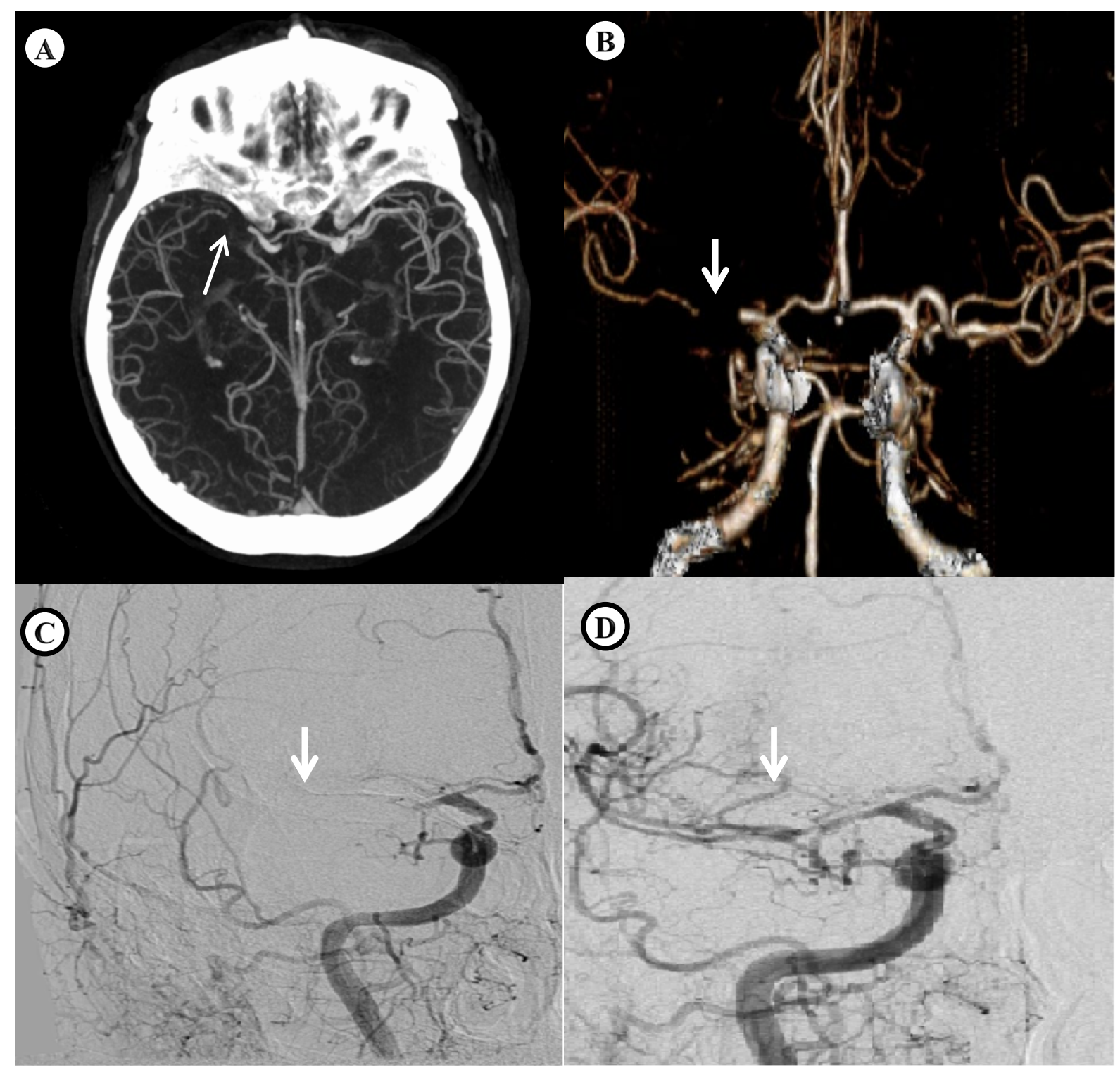


(4)

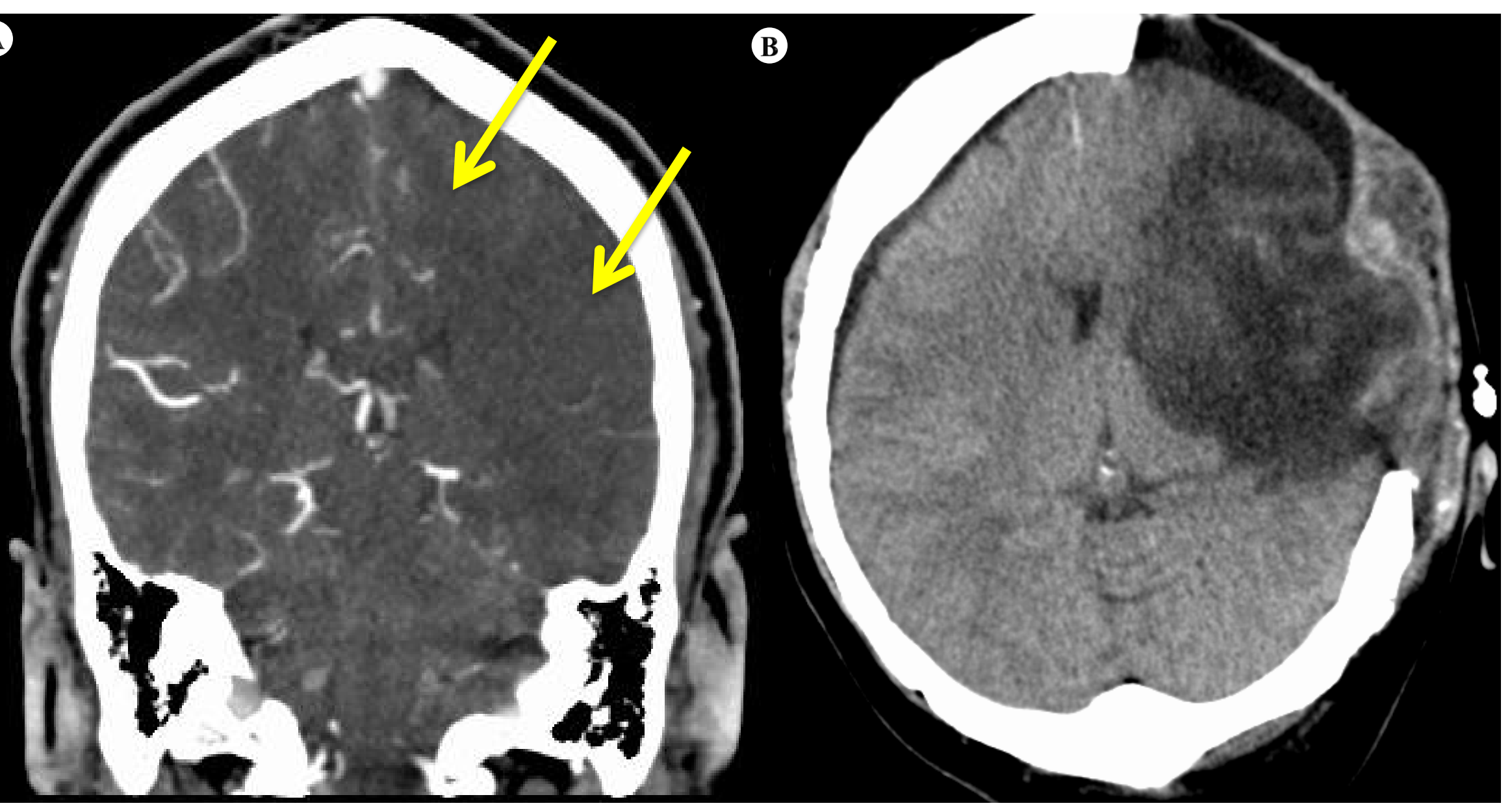




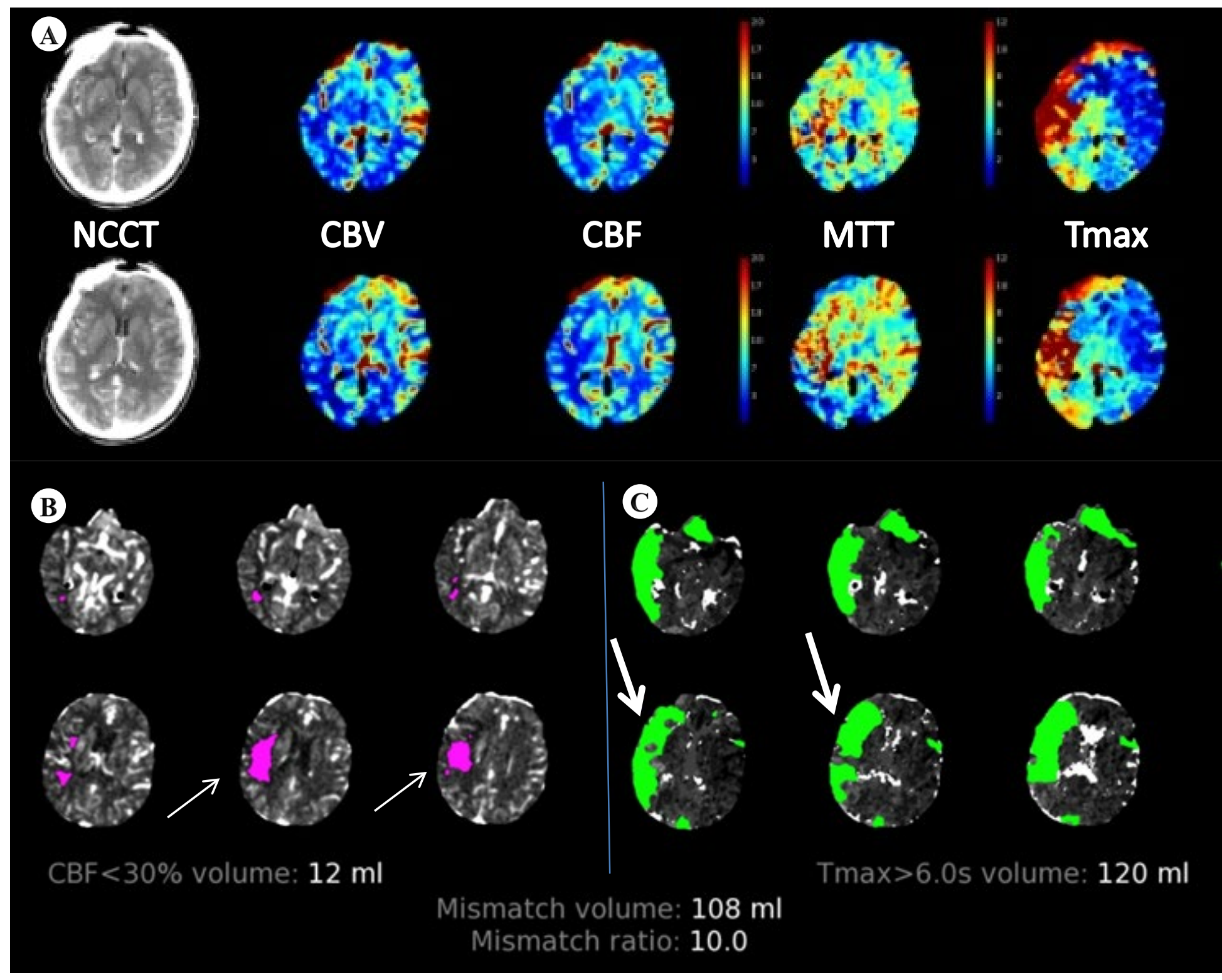




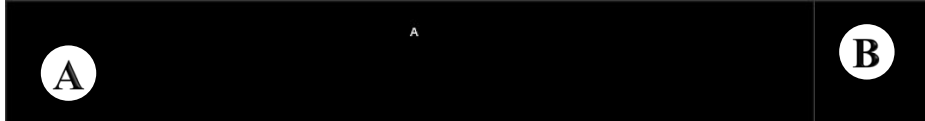

C
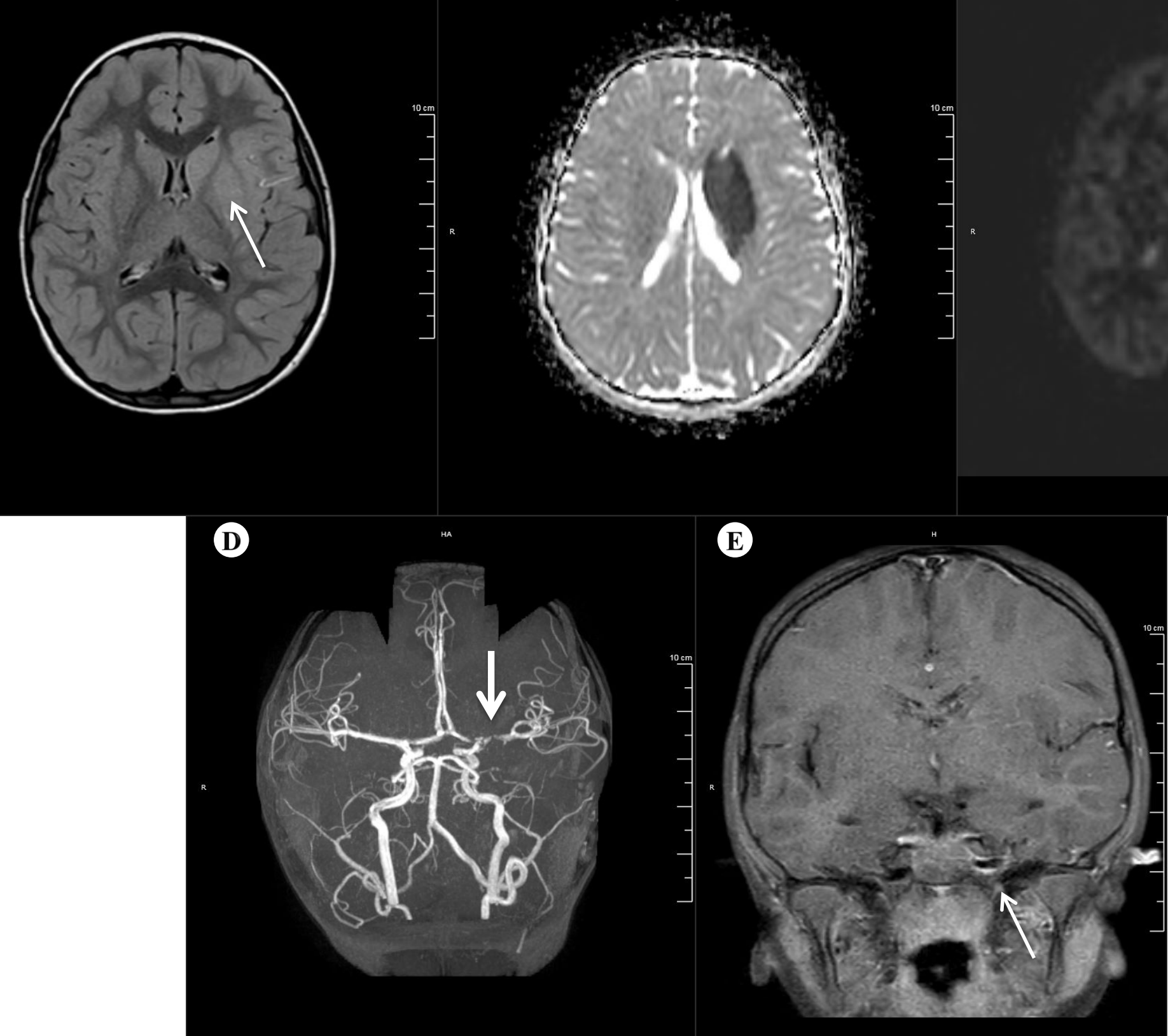


\begin{tabular}{|c|c|c|c|c|c|c|c|c|}
\hline Trial & MR CLEAN & EXTEND IA & SWIFT PRIME & WAKE UP & REVASCAT & ESCAPE & DEFUSE 3 & DAWN \\
\hline $\begin{array}{l}\text { Primary } \\
\text { Imaging } \\
\text { Modalities }\end{array}$ & $\begin{array}{l}\text { NCCT + CTA, } \\
\text { MRA, or DSA }\end{array}$ & NCCT, CTP & NCCT, CTP & MRI & NCCT, MRI & $\begin{array}{l}\text { NCCT, CTA } \\
\text { (multiphasic) }\end{array}$ & $\begin{array}{l}\text { CTA, CTP, MRI, } \\
\text { MRA }\end{array}$ & $\begin{array}{l}\text { NCCT, MRI } \\
\text { MRA, CTP, CTA }\end{array}$ \\
\hline $\begin{array}{l}\text { Treatment } \\
\text { Window }\end{array}$ & $<6$ hours & $<4.5$ hours & $<6$ hours & $\begin{array}{l}<4.5 \mathrm{hrs} \text {. after } \\
\text { symptom } \\
\text { recognition }\end{array}$ & $<8$ hours & $<12$ hours & 6-16 hours & $6-24$ hours \\
\hline $\begin{array}{l}\text { Main } \\
\text { Imaging } \\
\text { Criteria }\end{array}$ & $\begin{array}{l}\text { Proximal } \\
\text { occlusion }\end{array}$ & $\begin{array}{l}\text { Proximal } \\
\text { occlusion, Core } \\
<70 \mathrm{ml}\end{array}$ & $\begin{array}{l}\text { Proximal } \\
\text { occlusion, Core } \\
<50 \mathrm{ml}\end{array}$ & $\begin{array}{l}\text { DWI - FLAIR } \\
\text { Mismatch }\end{array}$ & $\begin{array}{l}\text { Proximal } \\
\text { occlusion, CT } \\
\text { ASPECTS } \geq 7 \text { or } \\
\text { DWI ASPECTS } \geq \\
6\end{array}$ & $\begin{array}{l}\text { ASPECTS }>6, \\
\text { moderate to } \\
\text { good } \\
\text { collaterals, } \\
\text { proximal } \\
\text { occlusion }\end{array}$ & $\begin{array}{l}\text { Target } \\
\text { Mismatch } \\
\text { Profile (core < } \\
70 \mathrm{ml} \\
\text { mismatch ratio } \\
>1.8 \text { and } \\
\text { mismatch vol. } \\
>15 \mathrm{ml} \text { ) }\end{array}$ & $\begin{array}{l}\text { Clinical } \\
\text { Imaging } \\
\text { Mismatch } \\
\text { (core }<21 \mathrm{ml} \text {, } \\
31 \mathrm{ml} \text {, or } 51 \mathrm{ml} \\
\text { depending on } \\
\text { age and NIHSS) }\end{array}$ \\
\hline Intervention & $\begin{array}{l}\text { Intra-arterial } \\
\text { Therapy vs } \\
\text { Standard Care }\end{array}$ & $\begin{array}{l}\text { Thrombectomy } \\
\text { vs Standard } \\
\text { Care }\end{array}$ & $\begin{array}{l}\text { Thrombectomy } \\
\text { vs Standard } \\
\text { Care }\end{array}$ & IV tPA vs None & $\begin{array}{l}\text { Thrombectomy } \\
\text { vs Standard } \\
\text { Care }\end{array}$ & $\begin{array}{l}\text { Thrombectomy } \\
\text { vs Standard } \\
\text { Care }\end{array}$ & $\begin{array}{l}\text { Thrombectomy } \\
\text { vs. Standard } \\
\text { Care }\end{array}$ & $\begin{array}{l}\text { Thrombectomy } \\
\text { vs Standard } \\
\text { care }\end{array}$ \\
\hline $\begin{array}{l}\text { Primary } \\
\text { Clinical } \\
\text { Outcome }\end{array}$ & $\begin{array}{l}90 \text { Day modified } \\
\text { Rankin Score }\end{array}$ & $\begin{array}{l}\text { 24-Hour } \\
\text { reperfusion }\end{array}$ & $\begin{array}{l}90 \text { day modified } \\
\text { Rankin Score }\end{array}$ & $\begin{array}{l}90 \text { day } \\
\text { modified } \\
\text { Rankin Score }\end{array}$ & $\begin{array}{l}90 \text { day } \\
\text { modified } \\
\text { Rankin Score }\end{array}$ & $\begin{array}{l}90 \text { day } \\
\text { modified } \\
\text { Rankin Score }\end{array}$ & $\begin{array}{l}90 \text { day } \\
\text { modified } \\
\text { Rankin Score }\end{array}$ & $\begin{array}{l}90 \text { day } \\
\text { modified } \\
\text { Rankin Score }\end{array}$ \\
\hline Comment & $\begin{array}{l}\text { Benefit of intra } \\
\text { arterial therapy. } \\
\text { Better outcomes } \\
\text { with good } \\
\text { collaterals on } \\
\end{array}$ & $\begin{array}{l}\text { CTP for patient } \\
\text { selection. } \\
\text { Benefit of early } \\
\text { endovascular } \\
\text { treatment. }\end{array}$ & $\begin{array}{l}\text { CTP for patient } \\
\text { selection. } \\
\text { Benefit of early } \\
\text { endovascular } \\
\text { treatment. }\end{array}$ & $\begin{array}{l}\text { Can use MRI } \\
\text { to determine } \\
\text { stroke age < } \\
4.5 \text { hours }\end{array}$ & $\begin{array}{l}\text { Extended } \\
\text { endovascular } \\
\text { treatment } \\
\text { window to } 8 \\
\text { hours }\end{array}$ & $\begin{array}{l}\text { Extended } \\
\text { endovascular } \\
\text { treatment } \\
\text { window to } 12 \\
\text { hours }\end{array}$ & $\begin{array}{l}\text { Extended } \\
\text { treatment } \\
\text { window to 6- } \\
24 \text { hours with } \\
\text { appropriate } \\
\text { micmatch }\end{array}$ & $\begin{array}{l}\text { Extended } \\
\text { treatment } \\
\text { window to } 24 \\
\text { hours with } \\
\text { appropriate } \\
\text { micmatrh }\end{array}$ \\
\hline
\end{tabular}

